\title{
TEACHING STYLE AND THE COLLEGE WRITING CLASS
}

\author{
Marjorie H. St. Rose \\ Humanities Division, The College of The Bahamas
}

This review questions the efficiency of the lecture method with particular reference to the teaching of English at The College of The Bahamas. Research studies and articles about current practice in college writing suggest that while the lecture method remains useful in subject areas dominated by transfer of large amounts of factual information, teaching methods in the English language arts have moved from product to process pedagogy, with a corresponding change from didactic to cooperative styles of teaching and learning. The writer recommends that college English classes utilize cooperative strategies.

\section{INTRODUCTION}

The College of The Bahamas plans to institutionalize the lecture method as the delivery system in a variety of subject fields traditionally taught in small groups of about twenty students. Expansion of the college population, along with the government's seeming reluctance to invest in the provision of additional classrooms account for the proposed use of didactic teaching techniques. Lecturing provides other benefits as well. For example, evaluation by multiple-choice tests becomes feasible as does the use of computers to grade tests. The College sees the use of the lecture method as a convenient solution to the problem faced by the institution as it seeks to provide training and educational opportunities for increasing numbers of students. Administrators envision the utilization of large lecture theatres capable of accommodating 80 to 100 students.

\section{THE LECTURE APPROACH}

Use of the large lecture format has important implications for all subjects, but particularly for the teaching of English and other communication arts. English teachers, especially those who affirm the value of recent trends towards cooperative, process-oriented pedagogy, resist strenuously the idea that language learning can effectively result from formal didactic methods. Recent research into the efficacy of the lecture format, while somewhat inconclusive, does suggest that other methods may be more appropriate, particularly in the area of language arts and communication.

Parker (1993) affirms the benefits of lecturing when used in conjunction with current knowledge about how humans process information. He outlines specific ways of applying such knowledge to enhance the delivery of a large amount of factual material. However, he includes an important caveat by indicating that a lecture may not consti- 
tute the best approach when communication and critical skills form the focus of instruction. Al-Hilawani, Marchant, and Poteet (1993) describe a study comparing the

effects on students' grades of the lecture format and reciprocal teaching. Their findings revealed no significant difference in grades on the basis of teaching method, but they note the instructor using reciprocal teaching had more time to assist individual students, so that qualitatively, reciprocal teaching surpasses lecturing. Also, they further note that the measure used (multiple-choice tests) may respond more favourably to the lecture method than to reciprocal-teaching.

Caston (1994) conducted a similar study comparing student outcomes when instructors used lectures only, with outcomes when lecturers used a mixed teaching repertoire of lecture, student-centered discussion, cooperative learning, and computer-assisted instruction. She found better attendance, slightly better grades, and higher levels of course completion using the lecture method. In spite of these mixed, inconclusive results, however, I think such outcomes as better attendance inevitably spring from the inherently teacher-centered nature of a lecture class. Students acknowledge their dependence on the knowledge-giving lecturer by ensuring attendance in class.

Shaughnessy (1995) substantiates this view by remarking that the locus of responsibility in a lecture class falls on the professor who "delivers" the knowledge. Shaughnessy explains that students can get high grades by "cramming" just before the exam, while practices such as eliminating the lowest grade or retaking tests allow students to get high scores. Miller (1991) questions the effectiveness of the lecture as a teaching method. He points out the advantages of the lecture: simplicity of preparation, sharing of data with large groups, and control of the flow and direction of the class.

However, he argues that personalized systems of instruction provide the basis for more favourable climates for learning and that the amount of teacher contact per student favours learning by enhancing students' feeling of ownership. However, Miller concedes that contextual issues such as teacher motivation, time requirements, and student enrollment and accountability must play a part in the selection of teaching techniques. He makes what I consider another important point when he states that the literature often does not deal with college teaching. I think that many teachers and members of the public view the college as an appropriate context for the use of lectures, but I do not necessarily agree.

An overview of these studies suggests that lecturing, though affirmed as a relevant teaching method in particular contexts, and though the research results appear inconclusive, may not apply as the teaching method of choice in modern classrooms. Lecturing as a part of the teacher's total repertoire appears acceptable, but using lectures to the exclusion of other methods may results in a less defensible position. By reviewing current aims and practices in English language arts at the college level, I shall demonstrate that interactive approaches to pedagogy provides a more appropriate methodology than the lecture method. 


\section{INTERACTIVE APPROACHES TO PEDAGOGY}

Some writers recommend the use of the lecture in the context of a multi-pronged approach. Stearns (1994) states that instructors feel compelled to lecture when teaching complex concepts but as a professor in communication studies asserts, the benefits of designing active learning techniques to encourage critical thinking skills and problem-solving. She goes on to say that active learning, while useful in a variety of contexts, assumes particular importance with highly complex materials because students often attain only lower-level learning of difficult material.

\section{Group Learning}

Stearns (1994) recommends using lectures only as one strategy in a cluster of strategies called the 1-2-3-4 technique, involving lecture, individual learning, small-group learning, and large-group learning. Effective use of groups results in quicker learning of complex materials than individual learning, and has the added advantage of promoting a positive atmosphere by motivating group members. Case studies form the basis of the learning experience.

\section{Utilizing Case Studies}

McDade (1995) also utilizes the case study approach to promote critical thinking and reflection, with discussion as the focus of the pedagogy. Learning consists of critical thinking rather than memorization of facts. Students actively involve themselves in their own learning process within a pedagogy that provides a context for that learning.

The case-study approach challenges students to identify assumptions about situations and about their own beliefs, to develop alternatives, and to explore these alternatives for strengths or weaknesses. I have found the case study approach particularly useful in teaching courses in Business Communication at the college level. Students consider different perspectives as they interact with their peers while a properly devised case study interests students, engaging their attention while allowing for fruitful integration of theory and practice. Students themselves may design their own case studies based on personal experience in the workplace or elsewhere.

\section{CONTENT-CENTERED, PRODUCT-ORIENTED INSTRUCTION}

The traditional approach to instruction in the English language arts has been content-centered as well as teacher-oriented. In this model, the teacher as disseminator or transmitter presents information that students periodically regurgitate in answers to test questions. Reinsmith (1994) argues that in this model, learning takes place on a superficial level; students and teachers are isolated. I see this type of teaching frequently. Novels and poems become comprehensive exercises with students trying to figure out 
what answers the teacher wants. A student may suggest a perfectly reasonable answer that fails to satisfy teachers because it does not fit exactly with the answer they have in the answer key or in their own heads. Students become frustrated and cynical when exposed repeatedly to such experiences. They learn to play the game, give the teacher the required answer, and lose the excitement of learning in a free and engaging atmosphere.

Applebee (1994) focuses on this dichotomy when he argues that English teachers want students to think for themselves yet at the same time, produce the right answer. The contradiction arises from the view of curriculum as a vehicle for the transmission of fixed knowledge. Many educators still defend this approach to curriculum. Various studies have shown that in spite of challenges to established views, the traditional orientation of the English language arts curriculum shows up in the relatively large number of canonical works that continue to hold a firm place in the curriculum in spite of attempts to include the works of minorities and women. For example, Applebee (1994) states that the content of English courses remains defined by the tradition; literary selections remain white, male, and Eurocentric, and the material expect "right answers" from students rather than thoughtful interpretations that might legitimately vary. My experience substantiates the traditional focus of the curriculum. In The Bahamas, a former British colony, the works of Shakespeare and other white, male, canonical writers still have an apparently unassailable position on the national school curriculum.

However, traditional content-centered, product-oriented pedagogies must eventually give way to more learner-oriented, process-focused teaching methods. The consensus has been building in favour of viewing language arts from a process perspective. Process pedagogy inevitably differs from product pedagogy, entailing revisions in classroom practice, in teacher role and in methods of evaluation.

\section{LEARNER-ORIENTED, PROCESS-FOCUSED TRAINING}

While on a conference on College Composition and Communication in Milwaukee, Wisconsin in March 1996, I noticed that a great deal of attention focused on innovative methods of assessment, such as self-assessment and portfolios, which encourage students to become involved not only in writing itself but in assessing their writing.

The National Council of Teachers of English (1996) recently published new standards for English language arts that reflect the process orientation of current teaching methods. The standards call for interaction with other readers and writers, and for communication with different audiences for a variety of purposes. Writers criticize and receive criticisms that form the basis for constant revision or recasting of their writing. Such activities improve their versatility and confidence as they move to other writing tasks. Clearly, the profession favours the move toward a new definition of curriculum and of teacher's role.

Recent scholarly writing reflects the new orientation. Bleich (1995) asserts that collaborative practices in teaching, learning, and research have become more common, as 
teachers recognize the new levels of accomplishments students can attain by working along with their peers and with their teachers. He acknowledges the rigidity of scholarly views that promote the ideal of the independent scholar and attributes this rigidity to sheer unwillingness to change, particularly in the context of the college classroom. However, he affirms the movement toward self-disclosure and subjectivity in the classroom as well as in published works. I think this change, while radical, has a great deal of potential power to reform current practices and to invigorate the intellectual climate in college classrooms (and elsewhere).

\section{Students Develop Their Own Voices}

The new pedagogy places greater emphasis on the student's development of her or his own voice, both in writing, and in oral situations. A number of strategies exist for empowering this voice, and teachers share these strategies through their own writing in journals and through presentations at conferences. Brookes (1993) describes a strategy called "town meetings" whereby his students articulate their thoughts in brief, threeminute presentations. In the traditional classroom, students' silence testified to their lack of power, which of course could not coexist with the teacher's assumption of power, but new approaches to learning in the English language arts classroom view speaking skills as a vital part of the social process of communication.

Process-centered teaching focuses on what students do rather than what they know and assumes that if students write often, on subjects of interests to them, they will gain confidence and skill as writers. The student writer is the expert, commanding subjects and strategies for composing that the teacher has no access to because the subjects and strategies are born of the writer's experience (Lindeman, 1995). Process teaching empowers students-by assuming that they can write, and gives them a safe space to write in. For example, grades lose importance and fail to exercise their usual tyranny because journals, freewriting, and other ungraded activities allow students time to. reflect and discover what they want to say. Portfolios replace the timed writing assignment on a topic chosen by teacher. Writing then becomes a more relaxed activity and loses its artificial aspect as something done for the teacher.

\section{Teachers Guide and Assist From the Sidelines}

Process-oriented teaching requires the teacher to become a dialogist, one who develops a firmly personal relationship with students. The teacher may also assume the role of a facilitator or guide. The more participatory and independent the student becomes, the more the teacher moves into the background, unobtrusively guiding and assisting from the sidelines.

\section{CONCLUSION}

Shrock and Shrock (1994) reject the didactic model consisting of a monologue in the teacher's voice that preempts students' questions and thought with unilateral teacher- 
centered discourse. They favour the dialogic teaching method in the context of fostering critical, analytical judgments, and skills in inquiry, listening, speaking, critical reasoning, and argumentation. My view is that the goals of teaching in the humanities require collective and cooperative learning strategies, discussion, and dialogue between teacher and student, as well as between student and student.

In today's world, the tendency to treat people as machines gains momentum every day. To combat this, teachers in the humanities and in language arts can use the new pedagogy to empower students to resist this process of dehumanization. In the area of English language arts, the literature reveals a distinct trend in the direction of cooperative, dialogic methods, and away from didactic instruction. Small classes and social learning enable students to develop their own voices, to listen critically to others, and to question everything. Students with such skills have a better chance to contribute meaningfully to society as well as to enjoy a more fulfilling personal life.

Surely, education in the 1990's should aim to produce people capable of critical, analytical thinking skills. The ability to memorize facts becomes increasingly redundant as the process of automation gains momentum in the technological age. The development of critical and problem-solving skills in college English classes necessitates the use of cooperative, personalized, small-group teaching strategies.

\section{REFERENCES}

Al-Hilawani, Y., Marchant, G., \& Poteet, J. (1993). Implementing reciprocal teaching: was it effective? (Report Series 1.10). Anderson, IN: The Midwest Association of Teachers of Educational Psychology. (ERIC Document Reproduction Service No. ED 363 614).

Applebee, A. (1994). Towards thoughtful curriculum: Fostering discipline-based conversation in the English language arts classroom. (Report Series 1.10). Albany, NY: National Research Centre on Literature Teaching and Learning. (ERIC Document Reproduction Service No. ED 366 945).

Bleich, D. (1995). Collaboration and the pedagogy of disclosure. College English, 57 (1), 43-61.

Brookes, G. (1993). Town meetings: A Strategy for including speaking in a writing classroom. College Composition and Communication, 44 (1), 88-92.

Caston, J. (1994). The learning experience: Impact on measures of institutional effectiveness. San Diego, CA: Annual International Conference of the League for Innovation in the Community College and the Community College Leadership program. (ERIC) Document Reproduction Service No. ED 375 907). 
Lindeman, E. (1995). Three views of English 101. College English, 57 (3), 287-302.

McDade, S. (1995). Case study pedagogy to advance critical thinking. Teaching of Psychology, 22 (1), 9-10.

Miller, M. (1991). Understanding basic teaching methods: Profile of discussion, lecture, and personalized systems of instruction. (ERIC Document Reproduction Service No. ED. 340 319).

National Council of Teachers of English. (1996). Standards for the English Language Arts. Urbana, NCTE.

Parker, J. (1993). Lecturing and loving it: Applying the information-processing model. Clearing House, 67 (1), 8-11.

Reinsmith, W. (1994). Archetypal forms in teaching. College Teaching, 42 (4), 31-36.

Shaughnessy, M. (1995). Delivery of the knowledge curriculum vs. skill and competency curriculum. (ERIC Document Reproduction Service No. ED. 384 286).

Shrock, a. \& Shrock, R. (1994). Engaging the past. Journal of American History, 81 (3), 1093-1098.

Stearns, S. (1994). College Teaching, 42 (3), 107-8.

\section{AUTHOR}

Marjorie St. Rose has been a lecturer at The College of The Bahamas since 1982. In her fifteen (15) years at The College, she has held the post of co-ordinator of Technical English; she has also served as Assistant Chairperson of Humanities Division from 1992 to 1996. She has taught a variety of courses in Language, Literature and Business communication.

At the University of The West Indies, Ms. St. Rose completed a Bachelor's degree in Special English, a post-graduate Diploma in Education, and a Certificate in Business Administration. She later did further studies at the University of Southern Mississippi, graduating with a Master's degree in Literature and Curriculum.

Her interests include profile assessment and co-operative learning strategies. 